\title{
Brain and Visceral Involvement during Congenital Cytomegalovirus Infection of Guinea Pigs
}

\author{
BRIGITTE P. GRIFFITH, ${ }^{(31)}$ HELEN L. LUCIA, AND G. D. HSIUNG \\ Department of Laboratory Medicine, Yale University School of Medicine, New Haven, CT and Virology Laboratory, \\ Veterans Administration Medical Center, West Haven, Connecticut, USA
}

\begin{abstract}
Summary
The virologic and histologic characteristics of congenital cytomegalovirus infection (CMV) were defined in 65 neonatal guinea pigs born from 27 mothers infected during pregnancy. Infectious virus or tissue lesions were present in $54 \%$ of the neonates tested. Guinea pig CMV was detected most often in the salivary glands $(72 \%)$ and spleen $(33 \%)$ of infected guinea pigs. Less frequently, virus was also detected in the brain, lung, pancreas and liver. Tissue lesions were most frequently observed in the brain and kidney, but also occurred in the salivary glands, liver, pancreas, thymus and spleen. The histopathology was identical to that observed in infants with congenital CMV infection. Infectious virus and histopathology were present in newborn guinea pigs born from mothers infected at any time during gestation. Newborns from mothers infected during early stages of gestation had virus present most frequently in the salivary glands, whereas offspring of mothers infected in late pregnancy had virus present in several tissues. Acute maternal guinea pig CMV infection produced generalized CMV infection of the offspring which was followed by persistent infection in neonatal salivary glands. Lesions remained present in several neonatal tissues including the brain. The long term consequences of such lesions in affected guinea pigs remain to be determined. The results of the study emphasize the similarities between human congenital $\mathrm{CMV}$ infection and congenital guinea pig CMV infection, thereby underlining the utility of this animal model as a means of understanding human congenital CMV infection.
\end{abstract}

Cytomegalovirus (CMV) is the most common cause of human congenital infection, involving $0.2-2.5 \%$ of live births $(11-13,19$, $22,27)$. Approximately $15 \%$ of the infected infants are born with or develop central nervous system damage. Severe CMV inclusion disease of humans is characterized by hepatosplenomegaly, hyperbilirubinemia, and involvement of the central nervous system $(5,10,11,12,13,14,23,29)$. In contrast, there may be no manifestations of the disease present in early infancy. The damage is not detected until late childhood when mild hearing loss or learning disabilities are discovered $(12,24,25)$.

There are many uncertainties in our understanding of the pathogenesis of congenital CMV infection. It is not known whether the time at which the virus gains access to the fetus is an important determinant in the prognosis. The potential role played by the virus in early interference with organogenesis as compared to destruction of fully formed fetal tissues has not been clearly established. Knowledge of these mechanisms has been hindered in large part by the lack of a suitable animal model of human CMV infection.

Intrauterine $\mathrm{CMV}$ infections have been reported in guinea pigs acutely infected with guinea pig $\operatorname{CMV}(3,9,16,18)$. Using this animal model of CMV infection, we have demonstrated that fetal infection occurred in utero regardless of the time of maternal infection (9). The present report centers on the study of congenital CMV infection at the time of birth in guinea pigs born from mothers acutely infected with guinea pig CMV at different stages of pregnancy. Both virologic and histologic aspects of congenital CMV infection are studied in these newborn guinea pigs. The occurrence and distribution of infectious virus are assessed in the various neonatal tissues and histologic lesions evaluated in the corresponding organs. The study establishes the degree to which congenital $\mathrm{CMV}$ infection in guinea pigs and congenital CMV infection in humans are analogous.

\section{MATERIALS AND METHODS}

Animal inoculation. The prototype strain of guinea pig CMV (No. 22122; American Type Culture Collection, Rockville, MD) was passaged in guinea pigs as described previously (9). One ml of salivary gland suspension, containing $5-6 \log _{10} \mathrm{TCID}_{50}$ of virulent salivary gland passaged guinea pig CMV, was inoculated subcutaneously into randomly bred pregnant Hartley strain guinea pigs (Camm Research Institute, Wayne, NJ). Pregnant guinea pigs inoculated with uninfected salivary gland suspension were used as controls. Blood samples were obtained from all animals before inoculation and were tested for the presence of neutralizing antibodies to guinea pig CMV. The pregnant animals used in this study were free of guinea pig CMV antibodies at the time of inoculation.

Sampling of tissues for virus isolation and histology. Various neonatal tissues including brain, thymus, lymph nodes, salivary glands, lung, liver, spleen, pancreas and kidneys were removed aseptically after sacrifice. For virus isolation, cell suspensions $(10 \%$ $\mathrm{w} / \mathrm{v}$ ) were prepared from parts of each tissue. Blood and urine were obtained as described previously (1). All samples were inoculated into four or five separate monolayer guinea pig embryo cell cultures, prepared from 20-40-day-old embryos as described previously $(3,15)$. All inoculated cultures were observed for 3-4 wk for evidence of virus-induced cytopathic effect. Viral isolates were identified by neutralization tests in cell culture using specific antiserum to guinea pig CMV (1).

For histologic studies, part of each tissue was fixed with Bouin's fixative or $10 \%$ buffered formalin, dehydrated through graded alcohols to xylenes and embedded in Paraplast. These blocks were sectioned and stained with hematoxylin and eosin.

\section{RESULTS}

Timing of maternal infection: number of live births, stillbirths and newborns examined. The average length of gestation in the guinea pig is 65-70 days. We have defined arbitrarily the first trimester as the first 20 days, the second trimester as $21-40$ days and the third trimester as day 41 to delivery. All pregnant guinea pigs were allowed to go to term. Their offspring were sacrificed within 15 days of birth, with most being studied within 3 days of birth. Newborns were isolated from the mothers immediately after birth so as to avoid a possible horizontal transmission. The number of live births, stillbirths and newborns examined is shown on Table 1. Neonatal deaths were significantly more frequent in the third trimester group (59\%) than in the first $(2 \%)$ and second $(11 \%)$ 
Table 1. Maternal infection at different stages of gestation: numbers of live births, stillbirths and newborns examined

\begin{tabular}{|c|c|c|c|c|c|c|c|}
\hline \multirow{2}{*}{$\begin{array}{c}\text { Time of } \\
\text { maternal infection } \\
\text { (trimester) }\end{array}$} & \multirow[b]{2}{*}{$\begin{array}{l}\text { No. of mothers } \\
\text { inoculated }\end{array}$} & \multicolumn{3}{|c|}{ No. newborn } & \multicolumn{3}{|c|}{$\begin{array}{l}\text { No. newborn processed } \\
\text { at birth }\end{array}$} \\
\hline & & Total & Alive & $\begin{array}{l}\text { Dead } \\
(\%)\end{array}$ & Total & Alive & Dead \\
\hline 1 & 11 & 43 & 42 & $1(2)$ & 31 & 31 & 0 \\
\hline 2 & 8 & 35 & 31 & $4(11)$ & 16 & 15 & 1 \\
\hline 3 & 8 & 32 & 13 & $19(59)$ & 18 & 13 & 5 \\
\hline Total & 27 & 110 & 86 & $24(21)$ & 65 & 59 & 6 \\
\hline
\end{tabular}

${ }^{1}$ Neonates were examined for the presence of virus and/or lesions.

trimester groups $(\mathrm{t}=5.53, P<0.001$ and $\mathrm{t}=4.13, \mathrm{p}<0.001$, respectively, Student's $t$ test). There were no neonatal deaths in the control group. All neonates were examined for infectious virus and lesions after sacrifice, except one neonate from the second trimester group and five newborns from the third trimester group who died at the time of birth. They were also processed for virus isolation and histology.

Virological studies. Infectious guinea pig CMV was recovered from 24/65 (37\%) of neonates born from mothers infected during pregnancy (Table 2). Infectious virus was isolated from offspring of mothers inoculated during any three trimesters. Furthermore, the number of newborns with infectious virus present in one or more tissues was not significantly different when the first, second or third trimester groups were compared.

The distribution of guinea pig CMV in the various tissues of infected neonates is shown on Table 3. Guinea pig CMV was recovered most frequently from the salivary gland (72\%) and the spleen (33\%). Infectious virus was also detected in the lung, pancreas, liver, brain and thymus of 4-12\% of infected newborns. Virus was not recovered from the kidneys but was present in the blood and urine of $1 / 24$ neonate. Virus was present in 13,15 , and $23 \%$ of the tissues of neonates whose mothers were infected during the first, second, and third trimester respectively. Guinea pig CMV was recovered more frequently from the salivary glands of neonates from mothers infected during the first and second trimester than the third trimester group. Six of 65 neonates examined for virus distribution were stillbirths. Only three of these six stillbirths showed virus infection. Virus was present in the spleen of the three neonates. Other organs infected included the liver and brain in one animal; pancreas in another; and lung, pancreas and liver in the third animal.

Histologic studies: neonates born from control mothers. The fixed tissues of fifteen newborns from mothers inoculated with uninfected salivary glands were used as controls. Liver, kidney, lung, spleen, lymph node, salivary glands, pancreas, adrenal, thymus, cerebrum and cerebellum were examined. Lesions were found only in the liver and lung. Ten of fifteen control newborns had mild fatty infiltration of the liver. The lungs of $6 / 14$ control newborns had patches where alveolar walls were thickened by mononuclear cells. No viruses were isolated from these newborns. Thus, these lesions were classified as nonspecific, rather than CMV related. Liver and lung changes similar to those noted in the control animals were observed in $6 / 59$ and $9 / 59$ of neonates born from CMV infected mothers. These changes were also categorized as nonspecific and were not included in the results on CMV related lesions.

Histologic studies: neonates born from virus infected mothers. Histologic lesions were observed in $46 \%$ of the newborns examined and were observed in offspring of mothers infected during any trimester (Table 2). Lesions were most frequently observed in the kidney and brain but also occurred in salivary glands, liver, pancreas, thymus and spleen. The histologic lesions seen were generally similar, regardless of the organ affected or the timing of maternal infection. The lesions consisted of areas of mononuclear cell infiltrate surrounding foci of necrosis, and varied in size ranging from foci of $20-40$ lymphocytes up to areas of cellular
Table 2. Incidence of infectious virus and tissue lesions in neonatal guinea pigs ${ }^{1}$ born from mothers infected at different stages of gestation

\begin{tabular}{cccr}
\hline $\begin{array}{c}\text { Time of maternal } \\
\text { inoculation } \\
\text { (trimester) }\end{array}$ & $\begin{array}{c}\text { Virus } \\
\text { recovery }\end{array}$ & $\begin{array}{c}\text { Histo- } \\
\text { pathology }^{3}\end{array}$ & $\begin{array}{c}\text { Virus recovery } \\
\text { or histo- } \\
\text { pathology }\end{array}$ \\
\hline 1 & $9 / 31(29)$ & $14 / 31(45)$ & $17 / 31(54)$ \\
2 & $8 / 16(50)$ & $6 / 15(40)$ & $8 / 16(50)$ \\
3 & $7 / 18(39)$ & $7 / 13(53)$ & $10 / 18(55)$ \\
Total & $24 / 65(37)$ & $27 / 59(46)$ & $35 / 65(54)$ \\
\hline
\end{tabular}

${ }^{1}$ Tested at age $1-15$ days.

${ }^{2}$ No. of newborns showed virus in one or more tissues/no. of newborns examined (\%).

${ }^{3}$ No. of newborns with lesions in one or more tissues/no. of newborns examined $(\%)$.

infiltrate and necrosis, $0.5-1 \mathrm{~mm}$ in diameter. Inclusions were found in animals infected in all three trimesters, but were rare. They were observed in kidney, thymus, spleen, and salivary gland.

Cerebral and cerebellar lesions were present in $15 \%$ of neonates examined (Fig. $1 a, b$ ). Some of these lesions were perivascular, consisting of a mononuclear cell infiltrate, mainly macrophages surrounding small blood vessels (Figure $1 a$ ). Lesions were observed in the kidneys of approximately $20 \%$ of the neonates (Fig. $2 a, b)$. Some lesions were present in the inner cortex and medulla where the normal renal anatomy was replaced by a mononuclear infiltrate, through which a few remaining tubules could be seen (Figure $2 a$ ). The renal tubular epithelium of one of the neonates contained Cowdry type A intranuclear inclusions (Fig. 2b). The liver of 7/56 neonates showed areas of cell infiltrate, scattered throughout the liver with no apparent preference for any particular zone of the lobule (Fig. $3 a$ ). In one neonate, the normal spleen architecture was replaced in some areas by clusters of macrophages; inclusions were noted in 2 nuclei (Fig. $3 b$ ). Areas of acute necrosis were observed in the pancreas of three of 38 neonates (Fig. 3c). The characteristic large inclusions of CMV were present in the salivary gland duct cells of some newborns (Fig. 3d). Others had only mononuclear cell infiltrates in the glandular interstitium, both within and surrounding the glandular lobules.

\section{DISCUSSION}

This paper describes the virologic and histopathologic characteristics of congenital CMV infection in guinea pigs. The analogies of congenital CMV infection in humans and guinea pigs are outlined in Table 4 . The results clearly show the similarities between congenital CMV infection in the two hosts. The risk of congenital infection following primary maternal infection during pregnancy has been estimated at $58 \%$ in humans (21), and is $54 \%$ in our study of guinea pigs. The spectrum of involvement of the different organs during congenital CMV infection appears to be similar in both hosts. Infants who die of acute fulminant CMV infection most commonly have involvement of the kidney, liver and lung (12). Three of six stillborn guinea pigs showed general- 
Table 3. Virus distribution in guinea pig CMV infected neonates

\begin{tabular}{|c|c|c|c|c|c|c|c|c|c|c|}
\hline \multirow{2}{*}{$\begin{array}{l}\text { Time of } \\
\text { maternal } \\
\text { infection }\end{array}$} & \multirow{2}{*}{$\begin{array}{l}\text { No. of mothers } \\
\text { with one or } \\
\text { more infected } \\
\text { neonates }\end{array}$} & \multirow{2}{*}{$\begin{array}{c}\text { No. of } \\
\text { infected } \\
\text { neonates } \\
\text { examined }\end{array}$} & \multicolumn{7}{|c|}{ No. of neonates showed virus in ${ }^{1}$} & \multirow{2}{*}{$\begin{array}{c}\text { No. of tissues } \\
\text { showed virus/ } \\
\text { no. of tissues } \\
\text { examined (\%) }\end{array}$} \\
\hline & & & Spleen & Lung & Pancreas & Liver & Brain & $\begin{array}{l}\text { Salivary } \\
\text { gland }\end{array}$ & Thymus & \\
\hline 1 & 5 & 9 & 2 & 1 & 1 & 0 & 0 & 8 & 0 & $12 / 90(13)$ \\
\hline 2 & 4 & 8 & 2 & 0 & 0 & 1 & 0 & 6 & 1 & $12 / 80(15)$ \\
\hline 3 & 5 & 7 & 4 & 1 & 2 & 2 & I & 4 & 2 & $16 / 70(23)$ \\
\hline Total & 14 & 24 & $8(33)^{2}$ & $2(8)$ & $3(12)$ & $3(12)$ & $1(4)$ & $18(72)$ & $3(12)$ & $40 / 240(17)$ \\
\hline
\end{tabular}

${ }^{1} 1 / 24$ neonate showed virus in blood or urine. $0 / 24$ neonate showed virus in the kidneys.

${ }^{2}(\%)$.
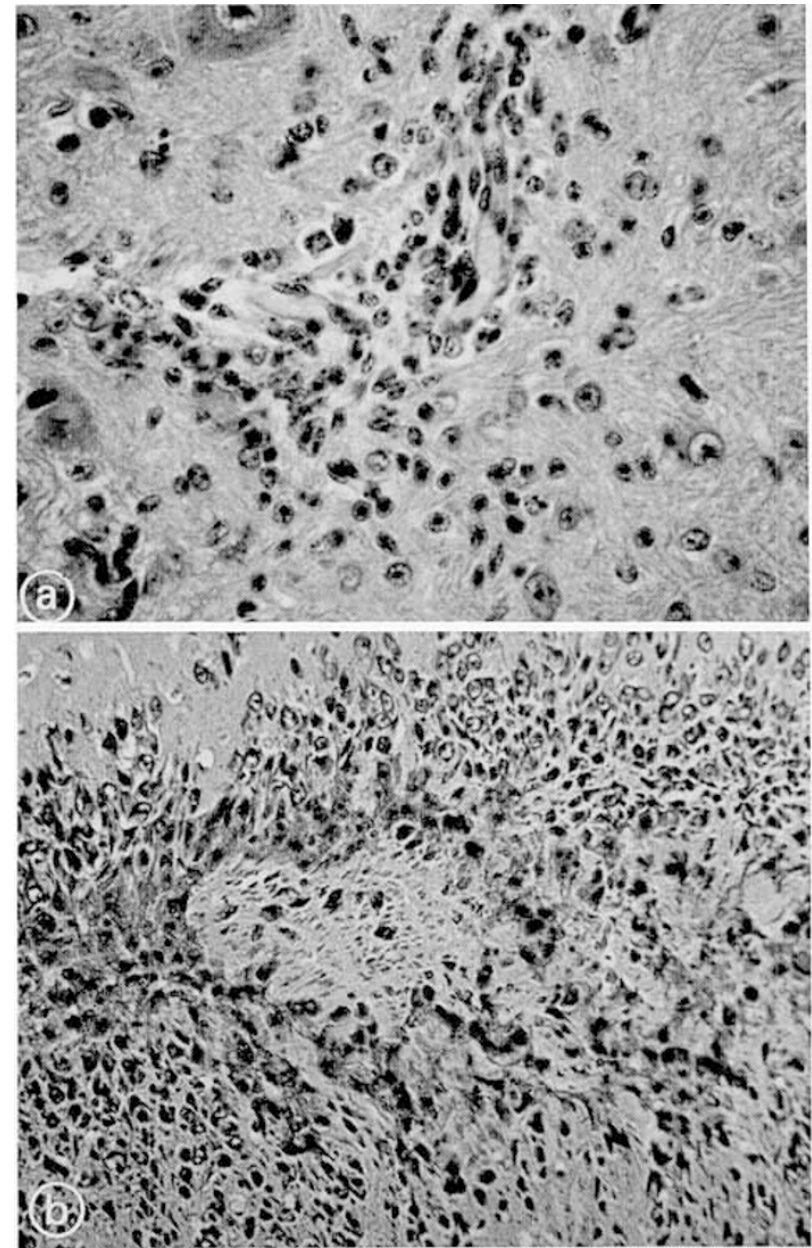

Fig. 1. (a), Cerebrum of newborn from mother infected during the first trimester of gestation $(\times 400)$. Marked perivascular infiltration by mononuclear cells. $(b)$, Cerebrum of newborn from mother infected during third trimester of gestation $(\times 200)$. Central area of necrosis surrounded by a large mononuclear cell infiltrate.

ized CMV infection. However, virus was not detected in the three other neonates, indicating that intrauterine growth and survival of the guinea pig fetus can be affected by systemic maternal CMV infection. The majority of infants with congenital human CMV infection only shed virus in the urine and/or saliva and do not have widespread involvement of many organs. Similarly, the majority of congenitally infected neonatal guinea pigs appeared asymptomatic at birth. We detected viruria in only one newborn, although most asymptomatic animals harbored virus in the salivary glands.

Similarities in the histology of the lesions seen during congenital $\mathrm{CMV}$ infection of humans and guinea pigs were also evident. The

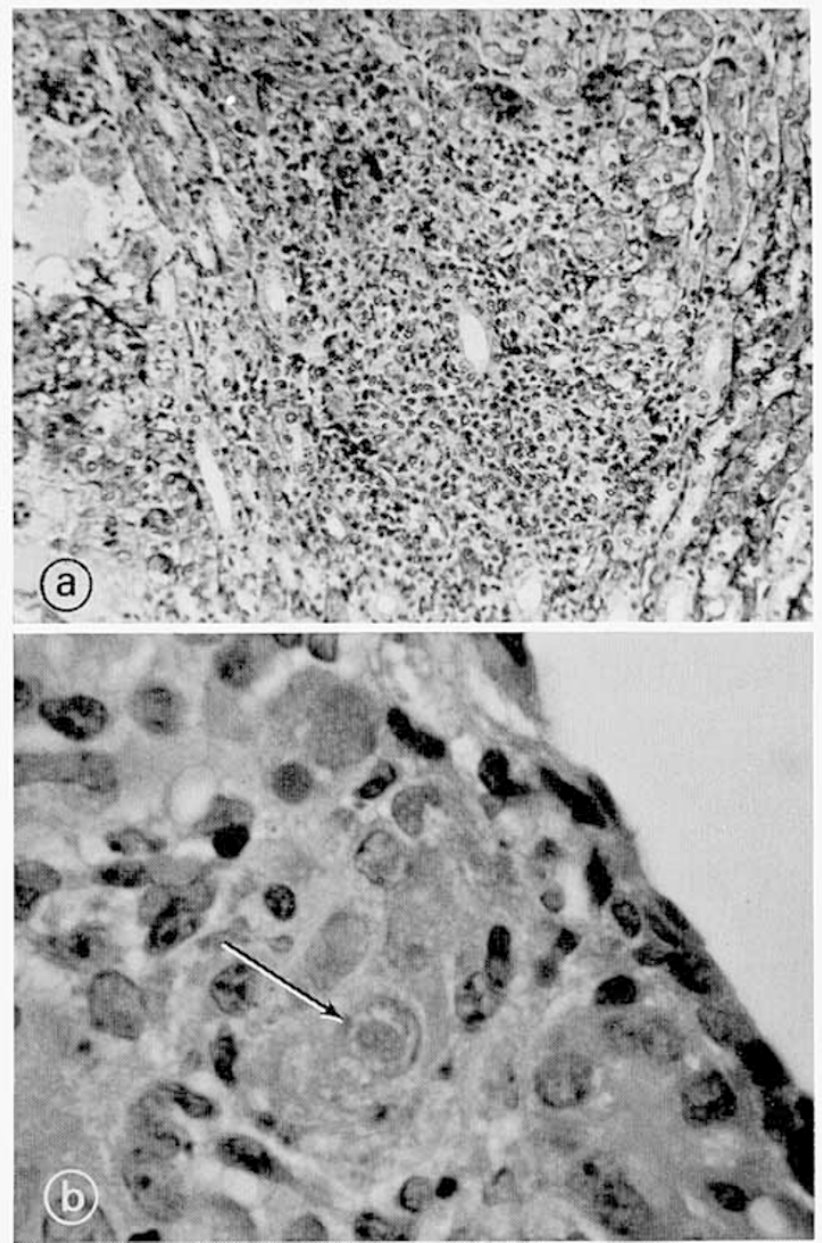

Fig. 2. (a), Kidney of newborn from mocher infected during the third trimester of gestation $(\times 100)$. Area of the medulla with loss of tubules and replacement with mononuclear cell infiltration. $(b)$, Kidney of newborn from mother infected during the first trimester of gestation $(\times 400)$. Inclusion in the nucleus of a remaining tubular cell in an area of loss of tubular cells, with mononuclear infiltration. Arrow points to inclusion.

histologic lesions seen in children with severe generalized congenital CMV infection were summarized by Hanshaw and Dudgeon (12). Epithelial cells of the renal tubules contain inclusions and mononuclear cell infiltration may be present in the kidney. The liver lesions of babies are described as areas of necrosis of the parenchyma and inclusions are occasionally seen within the hepatocytes. This corresponds to the renal and liver lesions seen in congenitally infected newborn guinea pigs. In addition, inclusionbearing cells surrounded by inflammation have been noted in the pancreas, thyroid, intestine, ovary, pituitary, parathyroid, thymus and salivary glands of babies with generalized congenital human 

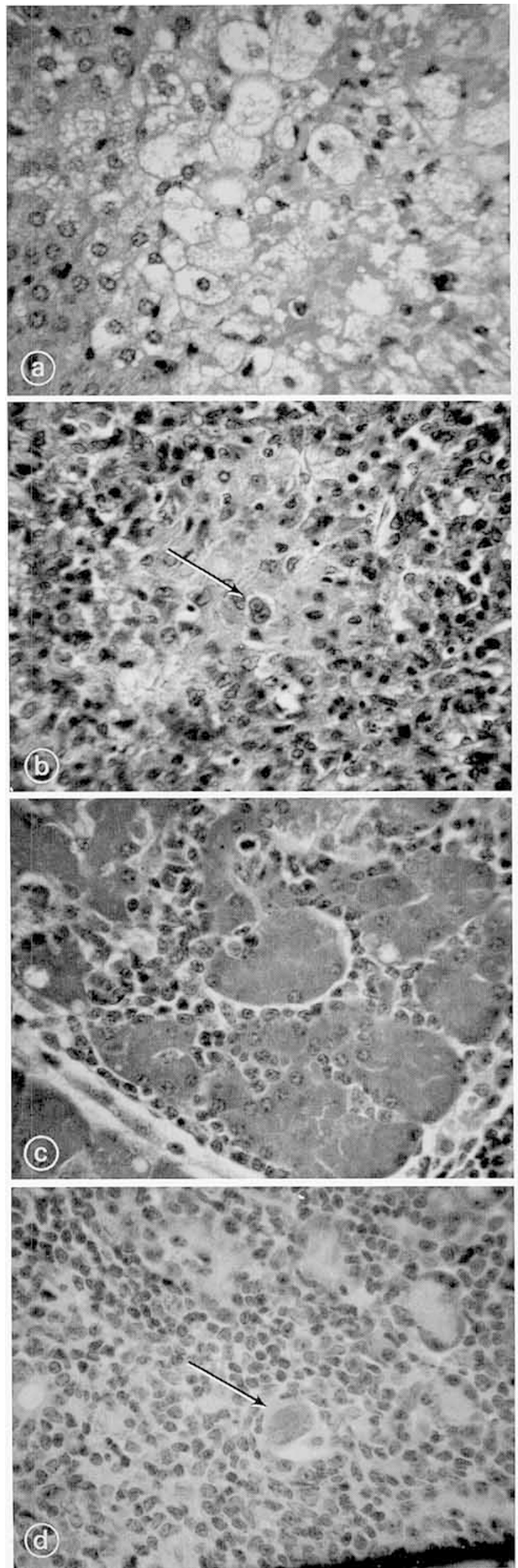

Table 4. Primary maternal CMV infection during pregnancy: comparison of congenital infection in humans and guinea pigs

\begin{tabular}{|c|c|c|}
\hline & Human $^{1}$ & $\begin{array}{c}\text { Guinea } \\
\text { pig }\end{array}$ \\
\hline $\begin{array}{l}\text { Congenital CMV infection after primary } \\
\text { maternal infecton }(\%)\end{array}$ & 58 & 54 \\
\hline \multicolumn{3}{|l|}{ Sites of involvement } \\
\hline kidney & + & + \\
\hline liver & + & + \\
\hline lung & + & + \\
\hline brain & + & + \\
\hline pancreas & + & + \\
\hline thymus & + & + \\
\hline salivary glands & + & + \\
\hline Viruria & + & \pm \\
\hline Severe generalized infections & + & + \\
\hline Subclinical infections & + & + \\
\hline
\end{tabular}

' References used: 2, 4, 5, 7, 12, 14, 21, 22, 28.

cytomegalovirus infection $(2,7,12,28)$. We found similar foci in the neonatal guinea pig pancreas, salivary gland, thymus and spleen.

The brain lesions in congenitally infected babies take two forms $(5,12,14,29)$. In one form, ependymal thickening and calcification of the subependymal mantle and adjacent white mantle are seen, usually in the lymbic area, but occasionally in the fourth ventricle as well. In the other form, an active glial nodule encephalitis is disseminated throughout the brain. These glial nodules occasionally contain a centrally located inclusion-bearing cell. Perivascular inflammation and periventricular gliosis may also be seen. Glial nodule encephalitis seems to be correlated with more active viral infection; the calcified lesions with older, inactive infection. The microscopic lesions seen in the congenitally infected guinea pigs correspond to the glial nodule encephalitis seen in congenitally infected babies. We have not seen any calcification in the guinea pigs. However, the total gestational period for guinea pigs is approximately 2 months. It is possible that this is not enough time for inactive calcified lesions to develop.

It has been reported that congenital human CMV infection may follow primary maternal infection occurring during any trimester $(4,8,20,21,27)$. However, data are not adequate to determine more precisely the risk during any particular trimester. Using the guinea pig model, Kumar and Nankervis (18) have reported that virus is present in neonatal lungs, spleen and brain following maternal infection during late gestation. In addition, Johnson and Connor (16) demonstrated transplacental passage only in mothers infected during the second trimester. We have evaluated, in a previous report, the effects of maternal infection at different stages of gestation (9). Fetal infection occurred in utero regardless of the time of maternal infection. Guinea pig CMV was detected most often in various fetal tissues, including brain, within 2 wk after inoculation of the mothers (9). In addition, offspring from mothers infected during early pregnancy usually had neutralizing antibodies, whereas newborns from mothers infected during the third trimester were born during acute maternal CMV infection and usually did not have detectable antibodies (9). The present study demonstrated that infection of guinea pigs at any time during gestation resulted not only in intrauterine fetal infection but also

Fig. 3. (a), Liver of newborn from mother infected during the first trimester of gestation $(\times 400)$. Necrosis and loss of hepatocytes with ballooning degeneration of the remaining hepatocytes. $(b)$, Spleen of newborn from mother infected during the third trimester of gestation $(\times 400)$. Area of destruction of the normal splenic architecture, with replacement by macrophages. Arrow points to inclusions. (c), Pancreas of newborn from mother infected during the second trimester of gestation $(\times 400)$. Loss of some acini with a mononuclear cell infiltrate. $(d)$, Salivary Gland of newborn from mother infected during the second trimester of gestation $(\times 400)$. Loss of acini, with a dense infiltrate of mononuclear cells surrounding the remaining acini. Arrow points to inclusion. 
in persistence of the virus in some fetuses throughout pregnancy and infection of the neonates at birth. It appeared that during the course of maternal guinea pig CMV infection, generalized infection first occurred in the progeny. The virus then disappeared progressively from most tissues to become persistent in the salivary glands of neonates. It is possible that maternal neutralizing antibodies are important in reducing the extent and severity of congenital guinea pig CMV infection. This is also analogous to human congenital CMV infection $(6,17,26)$.

The teratogenic effects of human $\mathrm{CMV}$ have been reviewed; direct interference with organ development has been difficult to demonstrate (10). Most of the disease manifestations in human congenital CMV infection has been associated with inflammation secondary to virus invasion. The histopathology observed in guinea pig neonatal tissues appeared to be lesions of fully formed tissues and did not include abnormalities of organ development. Often lesions were present at the time when no virus was recovered from the same tissue. The reasons for this are unclear. Only portions of each tissue were processed for either virus isolation or histology. Thus the results may reflect sampling variation, especially in the case when infectious virus or lesions are restricted to very localized areas. It is also possible that histologic lesions, which are the result of viral infection of some tissue, may remain present after viral clearance from that tissue. It is apparent that the brain tissue destroyed by these lesions remains lost to the animal after birth. The consequences of the loss of brain tissue are of particular importance and remain to be investigated.

The results of this study have underlined the similarities between congenital guinea pig CMV infection and human congenital CMV infection. Further study of this model should assist our efforts in understanding and preventing human congenital infection with CMV.

\section{REFERENCES AND NOTES}

1. Bia, F. J., Hasting, K., and Hsiung, G. D.: Cytomegalovirus infection in guinea pigs. III. Persistent viruria, blood transmission, and viral interference. J. Infect Dis., 140: 914 (1979)

2. Chang, C. H., Perrin, E. V., Hertzler, J., and Brough, A. J.: Cystadenoma of the pancreas with cytomegalovirus in a female infant. Arch. Pathol. Lab. Med., 104: 7 (1980).

3. Choi, Y. C. and Hsiung. G. D.: Cytomegalovirus infection in guinea pigs. II Transplacental and horizontal transmission. J. Infect. Dis., I38: 197 (1978).

4. Davis, L. E., Tweed, G. V., Stewart, J. A., Bernstein, M. T., Miller, G. L. Gravelle, C. R., and Chin, T. D. Y.: Cytomegalovirus mononucleosis in a first trimester pregnant female with transmission to the fetus. Pediatrics, 48: 200 (1971).

5. Elliott, G. B. and Elliot, K. A.: Observations on cerebral cytomegalic inclusions disease of the fetus and neonate. Arch. Dis. Child., 37: 34 (1962).

6. Embil, J. A., Ozere, R. L., and Haldane, E. V.: Congenital cytomegalovirus infection in two siblings from consecutive pregnancies. J. Pediat., 77: 417 (1970).

7. Farber, S. and Wolbach, S. B.: Intranuclear and cytoplasmic inclusions (protozoan-like bodies) in the salivary glands and other organs of infants. Am. J. Pathol., 8: 123 (1932).

8. French, M. L. V., Thompson. J. F., and White, A.: Cytomegalovirus viremia with transmission from mother to fetus. Ann. Int. Med, 86: 748 (1977).

9. Griffith, B. P. and Hsiung, G. D.: Cytomegalovirus infection in guinea pigs. IV.
Maternal infection at different stages of gestation. J. Infect. Dis., 14I: 787 (1980).

10. Hanshaw, J. B.: Developmental anomalies associated with congenital cytomegalovirus infection. Advances in Teratology, 4: 64 (1970).

11. Hanshaw, J. B.: Congenital cytomegalovirus infection: a fifteen year perspective. J. Infect. Dis., 123: 555 (1971).

12. Hanshaw, J. B. and Dudgeon, J. A.: Congenital cytomegalovirus. Major Probl. Clin. Pediatr., 17: 97 (1978).

13. Hanshaw, J. G., Scheiner, A. P., Moxley, A. W., Gaev, L., Abel, V., and Scheiner, B.: School failure and deafness after "silent" congenital cytomegalovirus infection. New Engl. J. Med., 295: 468 (1976).

14. Haymaker, W., Girdany, B. R., Stephens, J., Lillie, R. D., and Fetterman, G. H.: Cerebral involvement with advanced periventricular calcification in generalized inclusion disease in the newborn. J. Neuropathol. Exp. Neurol., 13: 562 (1954).

15. Hsiung, G. D., Tenser, R. B., and Fong, C. K. Y.: Comparison of guinea pig cytomegalovirus and guinea pig herpes-like virus: growth characteristics and antigenic relationship. Infect. Immun., 13: 926 (1976).

16. Johnson, K. P. and Connor, W. S.: Guinea pig cytomegalovirus: transplacental transmission. Arch. Virol., 59: 263 (1979).

17. Krech, U., Konjajev, Z., and Jung, M.: Congenital cytomegalovirus infection in siblings from consecutive pregnancies. Helv. Paediatr. Acta., 26: 355 (1971).

18. Kumar, M. L. and Nankervis, G. A.: Experimental congenital infection with cytomegalovirus: a guinea pig model. J. Infect. Dis., 138: 650 (1978).

19. Larke, R. P. B., Wheatley, E., Saigal, S., and Chernevsky, M. A.: Congenital cytomegalovirus infection in an urban canadian community. J. Infect. Dis., 142: 647 (1980).

20. Monif, G. R.. Egan, E. A., Held, B., and Eitzman, D. V.: The correlation of maternal cytomegalovirus infection during varying stages in gestation with neonatal involvement. J. Pediatr., 80: 17 (1972).

21. Monto, H.: Cytomegalovirus infections and diseases. Disease A Month 24: 1 (1978).

22. Numazaki, Y., Yano, N., Morizuka, T., Takai, S., and Ishida, N.: Primary infection with human cytomegalovirus. Virus isolation from healthy infants and pregnant women. Am. J. Epidemiol., 91: 410 (1970).

23. Pass, R. F., Stagno, S., Myers, G. J., and Alford, C. A.: Outcome of symptomatic congenital cytomegalovirus infection: results of long-term longitudinal follow up. Pediatrics, 66: 758 (1980).

24. Reynolds, D. W., Stagno, S., Stubbs, K. G., Dahle, A. J., Livingston, M. M., Saxon, S. S., and Alford, C. A.: Inapparent congenital cytomegalovirus infection with elevated cord IgM levels. Causal relation with auditory and mental deficiency. N. Engl. J. Med., 290: 291 (1974).

25. Stagno, S., Reynolds, D. W., Amos, C. S., Dahle, A. J., McCollister, F. P., Mohindra, 1., Ermocilla, R., and Alford, C. A.: Auditory and visual defects resulting from symptomatic and subclinical cytomegalovirus and toxoplasma infections. Pediatrics, 59: 669 (1977).

26. Stagno. S., Reynolds, D. W., Lakeman, A. W., Charamella, L. J., and Alford, C. A.: Congenital cytomegalovirus infection: consecutive occurrence due to viruses with similar antigenic compositions. Pediatrics, 52: 788 (1973).

27. Stern, J. and Tucker, S. M.: Prospective study of cytomegalovirus infection in pregnancy. Br. Med. J.. 2: 268 (1973).

28. Tidir, A. A., Levanyuk, V. F., and Kuruts, V. M. Involvement of the thymus gland in cytomegalovirus infection in infants. Arkhiv. Patologii (Russia), 40: 56 (1978).

29. Vortel, V. and Placy, V.: Glial nodule encephalitis associated with generalized cytomegalic inclusion body disease. Am. J. Clin. Path., 49: 319 (1968).

30. The authors gratefully acknowledge the assistance of Christine Cote, Jacquelyn Tillbrook and Roslyn Strauss.

31. Requests for reprints should be addressed to: Dr. Brigitte P. Griffith, Virology Lab./151 B. V. A. Medical Center, West Haven, CT 06516.

32. This research was supported by grant No. HD-10609 from the Institute of Child Health and Human Development, National Institute of Health. Brigitte P. Griffith is the recipient of Young Investigator Award AI-16028 from the Institute of Allergy and Infectious Diseases, National Institute of Health.

33. Received for publication July 17, 1981

34. Accepted for publication October 2, 1981 